\title{
AS TRANSFORMAÇÕES NO MUNDO DO TRABALHO FRENTE À GLOBALIZAÇÃO
}

\section{CHANGING WORLD OF WORK IN THE FACE OF GLOBALIZATION}

\section{Marcelo Alves Pereira Eufrásio}

\section{RESUMO}

Este trabalho pretende expor à questão da fragilização do trabalho frente às novas configurações econômicas, sociais e políticas que surgiram no final do século XX e vem se incrementando diante das realidades do século $X X I$, influenciado por um cenário perpassado pelas incertezas, desafios e impasses frente a atual problemática do mundo do trabalho, particularmente quando influenciado pela globalização. Nas ultimas duas décadas tem ocorrido marcadamente uma reestruturação do processo produtivo com a abertura das economias para competição global, internacionalização dos mercados financeiros etc., que estão associados à questão do processo de acumulação flexível de capital. Uma questão, que se evidencia diante desta realidade mundial que se reflete no panorama nacional e local é a intensificação da informalidade e da precarização das relações de trabalho, o que tem significado uma forte tendência das economias periféricas e emergentes, no entanto, quando essa problemática é pensada em determinadas regiões se constata uma forte tendência de fragilização dos espaços de constituição da garantia das ações políticas de deliberação e de garantia de direitos sociais, principalmente no tocante a proteção social do trabalhador, que se inicia com o acesso a escolarização e qualificação profissional, não oferecida em condições minimamente necessárias ao acesso à cidadania.

PALAVRAS-CHAVE: Globalização - Relações de Trabalho - Capitalismo flexível Direitos Sociais.

\section{ABSTRACT}

This paper aims to expose the matter of weakening of labor in the face of new economic, social and political settings that appeared in the late XX century and has 
been increasing against the realities of the XXI century, influenced by a scene that passes by the uncertainties, challenges and dilemmas facing the current problems from the labor world, especially when it is influenced by globalization. In the last two decades there has been a strongly productive process of restructuring with the opening of economies for global contest; financial markets internationalization, etc., which are associated with the issue of flexible process of the capital accumulation. One question which is evident on of this world reality which is reflected in national and local panorama is the increasing of informality and precariousness of labor relations, which has implied a strong tendency of peripheral and emerging markets. However, when this issue is considered in some regions it is found a strong trend of weakening of these spaces from the political security actions of deliberation and guarantee of social rights, mainly regarding of social protection of workers, which begins with access to schooling and professional training, not offered under conditions minimally necessary for citizenship access.

KEYWORDS: Globalization - Labor Relations - Flexible Capitalism - Social Rights.

\section{INTRODUÇÃO}

O fenômeno da globalização em suas diferentes vertentes (econômica, política, social e cultural) tem trazido acaloradas discussões sobre os destinos da humanidade frente às conseqüências de um modelo de sociedade globalizada, onde há uma crescente intensificação da fragilidade das relações humanas a partir da segregação e exclusão sociais, das garantias políticas e institucionais como a garantia à cidadania, além da substituição dos valores ético-filosóficos pelos valores mercadológicos. Nesse sentido, este trabalho visa apresentar uma abordagem acerca da globalização a partir da perspectiva sociológica, tendo como pano de fundo uma discussão sobre a problemática do trabalho no âmbito do capitalismo na contemporaneidade, que tem uma de suas conseqüências mais dramáticas o esvaziamento dos espaços de debate, criação e articulação política. 
A chegada da modernidade sob a perspectiva capitalista em sua dimensão global adveio principalmente a partir do legado das revoluções burguesas capitalistas e consequentemente com a efervescência da revolução industrial, que acabou configurando um conjunto de elementos de caráter político, social, econômico e cultural em suas diferentes perspectivas que se formaram a partir de um longo processo histórico ao qual ficou convencionado chamar de tempos de longa duração, conforme já afirmou outrora o historiador Fernand Braudel (MENDES, 1993).

Nesse sentido, a modernidade acabou carregando em si diferentes desafios e inquietações frente o destino do homem contemporâneo, dentre estas questões que merecem destaque na sociedade capitalista atual se encontra a dimensão do mundo do trabalho, principalmente quando se inserem as incertas sobre a problemática da flexibilização dos espaços políticos, econômicos e sociais.

Para entender a modernidade e suas dimensões estruturais a partir do fenômeno da globalização no mundo capitalista resolvemos trazer a discussão acerca da problemática do mundo do trabalho na atual conjuntura, para pensar sobre o contexto histórico e as conseqüências das mudanças porque tem passado a dimensão do trabalho, principalmente numa lógica excludente, que se permeia pela concentração de renda, consumo de bens e serviços, além de uma corrida desenfreada por atividades moldadas pelo lucro. Neste modelo que se instaurou a partir da globalização econômica serão discutidos desde aspectos como a natureza histórica do surgimento da globalização, o problema da fragilização dos espaços de deliberação política, principalmente a partir da despolitização do Estado frente às mudanças flexíveis advindas do mercado, além da problemática do trabalho a partir da precarização das relações de trabalho com o incremento da acumulação flexível do capital que tem fragmentado a noção de cidadania social e direitos sociais.

\section{ALGUMAS CONSIDERAÇÕES SOBRE A GLOBALIZAÇÃO}

A globalização se configura como um novo estágio na dinâmica capitalista de produção e organização do mundo instaurado após a efervescência do modelo de acumulação do capital, particularmente na atual conjuntura com sua face flexível (flexibilização da economia, das leis, das relações de trabalho, das relações de sociabilidade etc.), no entanto, essas mudanças do processo histórico capitalista 
não representaram mudanças eqüitativas do ponto de vista social, político ou econômico nas sociedades contemporâneas, na verdade, introduziram uma reconfiguração das necessidades mercadológicas de acumulação flexível do capital cuja conseqüência mais imediata é a liquidez dos valores políticos, jurídicos, culturais etc., das instituições e as relações sociais se moldando sob uma conjuntura moderna e globalizada (BAUMAN, 1999, 2000, 2006).

No entanto, este projeto de sociedade moderna não se instaurou repentinamente neste século $\mathrm{XXI}$, se trata de uma trajetória concebida paulatinamente sob a esteira do capitalismo, que se inicia e ganha dinamicidade a partir do incremento da globalização já na época moderna em pleno século XVI, quando surge o renascimento comercial e cultural (antropocêntrico e racionalista, esquecidos no período feudal) e a inserção do mercantilismo, das grandes navegações (via colonização dos Continentes americano, asiático e africano) e da formação dos Estados Nacionais na Europa. Aquele momento histórico se configura num contexto político, econômico, social e cultural propicio à formação de um novo paradigma econômico, que repercute nas demais camadas e setores da sociedade, principalmente como forma de consolidação do modelo estatal burguês na Europa.

Salienta lanni (1998) que este processo histórico capitalista teria passado por três momentos, sendo o primeiro quando da instalação na Europa do trabalho livre, a partir do capitalismo mercantil e da organização política moldada sob as bases dos Estados Nacionais modernos, por volta do século XVI, quando as estruturas pré-capitalistas foram substituídas pelo processo de acumulação de capital. No segundo momento, entraria a configuração do modelo industrial e a implantação do capitalismo em sua dimensão global a partir de finais do século XIX, principalmente a partir da difusão da internacionalização das relações de dependência econômica e política em sua vertente da política econômica imperialista, o que teria favorecido os processos neocoloniais (África e Ásia), bem como o incremento e a difusão de tecnologias que facilitaram a propagação do capitalismo industrial e suas zonas de influência, principalmente associadas à exploração do trabalho e acumulação de riquezas. Como terceiro e ultimo processo, destaca-se a derrocada dos modelos socialistas (reais) a partir de finais da década de 1980 e início dos anos 1990, e consolidação do modelo (neo) liberal econômico com o enfraquecimento dos Estados Nacionais a partir da racionalização econômica perpassada pela lógica 
internacional de fim das fronteiras territoriais e esvaziamento dos espaços políticos de deliberação supranacionais.

$\mathrm{Na}$ década de 1980 ao surgir a emergência de uma nova divisão internacional do trabalho, baseada na globalização econômica proporcionada pelas forças empresariais multinacionais, se incrementa gradualmente uma nova economia mundial, sendo que esse paradigma estrutural propõe a partir deste momento o incremento da economia dominada pelo sistema financeiro internacional em escala global, os processos de produção flexível e multilocais, baixos custos nos transportes, desenvolvimento das tecnologias de informação e de comunicação, desregulamentação das economias nacionais, sacralização das agências financeiras multilaterais e emergência do modelo capitalista das grandes transnacionais (SANTOS, 2005).

Este fenômeno global ultrapassa as fronteiras $\mathrm{e}$ as dimensões antes consideradas determinantes para constituição dos valores e tradições locais, como, por exemplo, a fragilidade dos Estados Nacionais a partir do esvaziamento dos espaços políticos, a desterritorialização das fronteiras nacionais, a subjetivação ou liquidez das identidades modernas (HALL, 1990; BAUMAN, 2006) e a descontinuidade dos processos de emancipação e promoção dos espaços do mundo do trabalho a partir da transição do paradigma da "sociedade informacional" em detrimento da "sociedade salarial", conforme lembra Castel (1990). Nesta dimensão (pós) estrutural, ressalta Bauman $(2000$, p. 68 ; 112) que se "a modernidade é um quadro inerentemente 'transgressor' que rompeu muita fronteira firme e segura", nestes termos, "a sociedade não pode fazer felizes os seus indivíduos; todas as tentativas (ou promessas) históricas nesse sentido geraram mais miséria que felicidade".

A globalização ${ }^{1}$ trouxe consigo novos paradigmas, conforme lembra Beck (1999) de que a após a queda do muro de Berlim e a derrocada do modelo soviético, o elemento que impera no contexto global não é o fim da política, mas sim a exclusão da política do quadro categorial do Estado nacional dos debates contemporâneos. O que se torna preocupante, pois o discurso da globalização

\footnotetext{
${ }^{1}$ Em seu livro O que é Globalização? Equívocos do globalismo: respostas à globalização (1999), Ulrick Beck ressalta que a categoria globalismo "designa a concepção de que o mercado mundial bane ou substitui, ele mesmo, a ação política; trata-se, portanto da ideologia do império do mercado mundial, da ideologia do neoliberalismo" (p. 27).
} 
tangencia as necessidades e deliberações antes construídas pelas premissas do Estado de bem-estar social, voltadas à proteção social, aposentadoria, assistência social, infra-estrutura comunitária, política e organização dos sindicatos, inclusive para deliberar sobre as negociações salariais, voltando-se agora para uma poderosa força econômica verticalizada e estruturadas sob as bases do mercado, da economia, das finanças e da informação.

Esta transformação estrutural no cenário global traz consigo uma alarmante constatação, conforme destaca o sociólogo Ulrick Beck (1999, p. 14), para pensar a política da globalização como tendência das leis do mercado global no século XXI:

Pode-se então afirmar: a questão da globalização na virada para o século XXI representa, para as empresas que fazem negócios transnacionais, o mesmo que a questão das classes sociais representava para o movimento dos trabalhadores no século XIX, mas com uma diferença essencial: enquanto o movimento dos trabalhadores atuava como poder de oposição, as empresas globais atuam até este momento sem oposição (transnacional). [...] o aparecimento da globalização permite aos empresários e suas associações a reconquista e o pleno domínio do poder de negociação que havia sido politicamente domesticado pelo Estado do bem estar social capitalista organizado em bases democráticas.

Os novos padrões de sociabilidade e de concepção do exercício do Estado nacional se expressa na volatilidade das relações políticas, jurídicas, comerciais etc., o caso, por exemplo, da taxação de impostos é um exemplo particular do "drama político" porque passam os governos locais, visto as empresas transnacionais não se constituem com os mesmos elementos organizacionais de uma empresa tradicional, materiais-primas, planejamento, montagem, taxação de impostos etc., na verdade, funciona em lugares ou países diferentes, o que repercute no momento de pagarem impostos ou exigir investimentos públicos de infra-estrutura em uma destas localidades.

Essa reconfiguração do espaço político global adveio de uma nova trajetória econômica da política "pró-mercado" que trouxe também significativas mudanças para o sistema interestatal, se por um lado se comprimiu as forças deliberativas dos Estados hegemônicos para controlarem as instituições financeiras multilaterais, por outro, abriu o precedente para acordos políticos interestatais de forma que a soberania evoluiu para soberania conjunta ou partilhada entre os Estado Nação e 
os organismos econômicos supra regionais como a União Européia, NAFTA, Mercosul etc. (SANTOS, 2005) ${ }^{2}$.

Bauman (1999) identifica este processo de fragilidade dos modelos governamentais como sendo uma nova expropriação, dessa vez do Estado, visto que nesta conjuntura atual este ente público passa a exercer novas atribuições como de "policiamento do território e da população" em detrimento do gerenciamento das demais atribuições até então de responsabilidade dos governos nacionais. Se na década de 1970, as empresas corriam atrás dos governos para negociar benefícios e infraestrutura operacional, atualmente os governos locais é que correm atrás das empresas, frente a isso, lembra Nascimento Neto (1996) que na década de 1990 as dez maiores corporações mundiais - Mitsubishi, Mitsui, Itochu, Sumimoto, General Motors, Marubeni, Ford, Exxon, Nissho e Shell, chegavam a faturar o equivalente ao Produto Interno Bruto do Brasil, México, Argentina, Chile, Colômbia, Peru, Uruguai e Venezuela juntos, uma tendência que se agravará na década seguinte.

A reflexividade como uma dinâmica que se insere no bojo do fenômeno da modernidade, principalmente neste momento de ameaça da despersonalização dos espaços públicos e políticos, deve conduzir a uma reflexão critica que se torna ferramenta imprescindível para entender as dinâmicas existentes nas instituições políticas, sociais e econômicas. Ainda sobre essa questão Bauman (2000, p. 90) entende que os espaços políticos são construções reflexivas que se exercem em terrenos democráticos, assim:

a reflexão critica é a essência de toda autêntica política (enquanto distinta do meramente "político", isto é, do que está ligado ao exercício do poder). A política é um esforço efetivo e prático para subjugar instituições que exaltam a validade de fato do teste de validade de jure. E a democracia é um local de reflexão critica que extrai sua típica identidade dessa reflexão.

\footnotetext{
2 Boaventura de Sousa Santos (2005, p. 45) citando Bob Lessop identifica três tendências gerais de transformação do poder do Estado, a desnacionalização do Estado (esvaziamento do aparelho do estado nacional em função da reorganização); a des-estatização dos regimes políticos (com a transição do conceito de governo para governança e a gradativa associação entre governos, para-governos e não-governos), e, finalmente, a internacionalização do Estado nacional (conforme as necessidades advindas das exigências extraterritoriais ou transnacionais para adequar a ação do Estado nacional a essa lógica global).
} 
O modelo de sociedade democrática que articula os espaços deliberativos de exercício da política não é possível sob o paradigma econômico da globalização. Para Castoriadis (apud BAUMAN, 2000, p. 90) é necessária uma sociedade livre e mais justa possível que se articule continuamente em suas ações políticas, logo, "é a esse movimento que chamo projeto de uma sociedade autônoma, o qual, se quiser vingar, tem que criar uma sociedade democrática". Frente ao contexto que ora se insere de valores e sentidos políticos líquidos e vazios em suas propostas de inserção do debate democrático, que a proposta de Bauman (2000, p. 90) aparece como um alerta e uma conclamação aos ideais de emancipação tão necessários aos padrões e necessidades atuais, principalmente quando "a política e a democracia que existem de fato são tão distantes dos modelos ideais como as sociedades contemporâneas em relação ao modelo de uma sociedade autônoma".

A liquefação (ou liquidez) do Estado, enquanto ente político-governamental, bem como das relações sociais e dos valores humanos é uma constante em países do mundo globalizado, sua tendência tem sido pela flexibilidade das relações políticas, sociais, econômicas, culturais e até identitárias, conforme destacou Hall (1990) a partir dos seus estudos sobre a identidade na pós-modernidade, neste sentido, as conseqüências deste processo globalizante é a fragilidade dos espaços de deliberação, negociação e articulação política que repercutem sensivelmente em elementos vitais para o funcionamento da sociedade, principalmente quando se insere a questão das relações de trabalho no mundo cada vez mais globalizado.

\section{ESVAZIAMENTO DO ESPAÇO POLÍTICO?}

A tendência pela flexibilização das relações políticas, econômicas e sociais no mundo global, conseqüência desta fluidez e liquefação das estruturas ora já estudadas traz a tona o problemática do mundo do trabalho. A configuração atual em que se insere o contexto das relações de trabalho esta mergulhado na dinâmica da "sociedade informacional", uma conjuntura marcada pela transição do mundo do trabalho que outrora foi formado pela empregabilidade e sindicalização, e, que passa a constituir-se via globalização num novo paradigma de volatilidade e insegurança social (CASTEL, 1998; CASTELLS, 1990). 
Segundo Castells (1990) o novo paradigma informacional do trabalho e da empregabilidade é difuso, perpassado pela interação histórica entre elementos como a transformação tecnológica, a política das relações industriais e ação social conflituosa. Neste caso, a questão do emprego passa a se articular a partir das necessidades da economia global e não apenas tendo como critério seu avanço informacional, desse modo, o capital flutua nas redes financeiras globais e determinam como deve ser o trabalho em diferentes regiões, o que torna a questão do trabalho limitado frente às instituições, culturas, fronteiras etc.

Nesta tendência do capital flexível frente ao trabalho e a divisão informacional, acaba levando os trabalhadores a tornarem-se subjugados às jornadas flexíveis, pois ainda segundo o autor da obra Sociedade em rede (CASTELLS, 1990) a reestruturação produtiva de empresas e organizações introduziu uma mudança fundamental, a individualização das relações de trabalho no processo de trabalho, que é contrário a tendência histórica de assalariamento do trabalho e socialização da produção, uma tendência correspondente a descentralização das tarefas e polivalência nas funções (SENNET, 2006). A conseqüência direta deste processo é a constituição de uma força de trabalho permanentemente formada por dirigentes e administradores, e, uma mão de obra disponível e volátil, que se insere na realidade dramática da precarização das relações de trabalho, como trabalhador temporário, subcontratado, meio-expediente, terceirizado etc.

Frente a essa constatação de que a sociedade contemporânea é marcada pela redefinição (leia-se fragilização/precarização) das relações de trabalho, principalmente para adaptar-se aos interesses da sociedade informacional no contexto da globalização, é que a partir deste fenômeno que ganha dimensões extraterritoriais e supranacionais se instituiu uma vertente flexível (tanto da acumulação de capital quanto seus elementos de articulação político-econômica) e que em função das conseqüências trágicas da flexibilização econômica, política, reguladora (jurídica), social etc. aparecem elementos aviltantes da condição proletária, ou seja, "uma situação de quase-exclusão do corpo social" conforme observou Castel (1998). Diante desta problemática incursa na história é possível constatar que a sociedade ora concebida não inseriu em sua plataforma de intenções um projeto de solidificação das estruturas sociais de garantia dos direitos sociais, que 
são conseqüência também da fragilidade dos espaços políticos de direitos políticos e civis. Como afirmou Bourdeau (2001, p. 60 apud OLIVEIRA, 2009, p.20, grifo nosso):

\begin{abstract}
Tudo o que se descreve sob o nome ao mesmo tempo descritivo e normativo de 'globalização' é efeito não de uma fatalidade econômica, mas de uma política consciente e deliberada, mas o mais das vezes inconsciente de suas conseqüências. Totalmente paradoxal, uma vez que se trata de uma política de despolitização, essa política que bebe desavergonhadamente no léxico da liberdade, do liberalismo, da liberalização, da desregulamentação visa conferir um predomínio fatal aos determinismos econômicos, liberandoos de todo controle, e submeter os governos e os cidadãos às forças econômicas e sociais assim 'liberadas'.
\end{abstract}

A política de despolitização adotada pelo modelo atual reforça aspectos políticos, econômicos, sociais e culturais de dimensões globais que advoga pelo esvaziamento do debate político, conseqüência da política da globalização econômica, na perspectiva do processo de 'exclusão da política' do espaço do Estado Nacional conforme advertiu Oliveira (2009), que inscreve a questão social à "subpolítica"3 de inferiorização da promoção dos cidadãos. Um modelo de sociedade capitalista industrial que não emplacou na concretização do nível de cidadania plena, em sua dimensão de cidadania universal, isto é, com a participação política, a formalização e garantia de direitos e deveres concernentes às condições de reprodução dos interesses e necessidades coletivas.

No bojo desta discussão está o problema da estagnação política que proporcionou uma situação de marginalização dos trabalhadores que se inserem num contexto ainda mais desafiador quando pensado sob a lógica da informalidade, sendo que o impor acaba sendo o descontrole das ações de mobilização e reivindicação social, bem como de corporativismo entre as relações de capital e trabalho, inserindo um contexto de indefinição das relações de trabalho.

Ao insurgir o cenário da década de 1990 com o modelo de "Estado mínimo" com base no neoliberalismo, as indeterminações do mercado volátil, da livre negociação e da ausência do Estado nas questões econômicas oferecem uma situação de fragilidade ainda maior das relações de trabalho. O contingente de

\footnotetext{
${ }^{3}$ Adverte Beck (1999) que o poder das empresas transnacionais visando interesses econômicos e especulativos subverteu a necessidade de proteção normativa ou regulamentadora, pois seus interesses estão acima das mudanças legislativas ou constitucionais, o que impede qualquer processo revolucionário ou de debate público, o que justifica a idéia de "subpolítica" frente ao poder de negociação nos termos da autogestão das atividades econômicas no contexto da sociedade mundial.
} 
trabalhadores desempregados, subempregados e em condições de informalidade representa grupos do exército industrial de reserva ou superpopulação relativa excedente conforme destacou Marx (1996).

\section{A PROBLEMÁTICA DO TRABALHO E MODELO GLOBAL DE FLEXIBILIZAÇÃO}

A flexibilização da acumulação de capital representa uma nova configuração na produção e nas formas de conceber os valores sociais, econômicos e culturais, que caminham para um regime de flexibilidade das formas de produtividade, resultantes do modelo de desenvolvimento (neo) liberal e produtivista. Nessa perspectiva, o modelo econômico tornou possível a transição do século XX para o século XXI a partir da reorganização geopolítica do capitalismo, principalmente com processo de reprodução da vida social por meio da produção de mercadorias que envolvem de alguma forma todas as pessoas inseridas no mundo capitalista.

A primeira constatação da precariedade das relações de trabalho no século $X X$, no mundo capitalista foi verificada no conjunto de estudos da Organização Internacional do Trabalho - OIT, conforme lembra Souza (1982), aqueles relatórios se inseriam no programa mundial de emprego, uma ação política criada em 1969 que tinha como principal objetivo propor estudos sobre estratégias de desenvolvimento econômico para criação de empregos. Nos estudos da OIT, principalmente no relatório de emprego e renda sobre o Quênia se verificou fundamentalmente uma reflexão sobre o conceito de setor informal, por detalhar com maior precisão quais condições caracterizam as atividades e os trabalhadores informais. Desse modo, este estudo serviu como referencia para atividades em países da África e Ásia, bem como para trabalhos realizados pelo Programa Regional de Emprego para América Latina e Caribe - PREALC, e pelo Banco Mundial.

Essas relações de trabalho na conjuntura das ultimas décadas fez surgir um processo acentuado de mão de obra excedente, que alimentará o processo de informalidade dentro das dinâmicas do mundo do trabalho. Entende Soares (2008, p. 44) que: 
É importante observar que boa parte do discurso atual trata esses mesmos homens e mulheres como responsáveis pelo estado em que se encontram, esquecendo-se do processo histórico que influiu neste resultado, e das leis de funcionamento do capitalismo que produzem o "Exército Industrial de Reserva". Mais que isso, atribuem as formas precárias de assegurarem a sobrevivência como o trabalho informal, como "alternativas" de trabalho, e não como determinações imperativas do capitalismo.

A tendência com o capitalismo não é de garantia de emprego para todos os indivíduos, pois há possibilidade de que diferentes formas de trabalho coexistam contemporaneamente no contexto do mercado capitalista. Nesta perspectiva Soares (2008) defende que podem existir diversos exemplos de relações de trabalho que foge do assalariamento, mas que partem do pressuposto da produção. Assim, com o crescimento populacional surge o desemprego, principalmente no cenário brasileiro de tradição corporativista do trabalho formal, uma vez que os investimentos não são capazes de absolver toda mão de obra disponível, desse modo, surge uma grande qualidade de jovens ociosos e de trabalhadores dispensados.

Nesta perspectiva, diante de alterações no âmbito econômico e político nacional e internacional como, por exemplo, da crise financeiro-econômica do final de 2008, já se vislumbra uma sensível tendência de flexibilização das relações de trabalho diante do arrocho salarial e do desemprego, o que faz crescer o trabalho informal de forma ainda mais incisiva. Segundo Oliveira (2010) a problemática da informalidade nas relações de trabalho mantém-se em permanente evidência no contexto brasileiro, principalmente depois de variadas alterações nas formas e intensidade com que se manifesta tal problemática. O que faz surgir uma série de questionamentos sobre o tema da informalidade $\mathrm{e}$, consequentemente, sobre categorias como "trabalho informal", "informalização", "nova informalidade" entre outros pressupostos e categorias.

Conforme lembra Druck (et. al. 2004, p. 212), o termo informalidade se constitui num dos mais polêmicos da literatura de economia e sociologia do trabalho, que comportam ao longo da história, inúmeros e significativos usos ${ }^{4}$. Não sendo um

\footnotetext{
${ }^{4} \mathrm{O}$ termo informalidade é ainda por demais polissêmico e se constitui num termo ainda problemático de conceituá-lo, tendo em vista suas diferentes dimensões, dinâmicas, arranjos e contextualizações na perspectiva do modelo capitalista ou fora dele (NORONHA, 2003; FILGUEIRAS; DRUCK; AMARAL, 2004; HIRATA; MACHADO, 2007).
} 
tema pacífico diante dos elementos que metamoforseiam as relações de trabalho no âmbito do capitalismo globalizado, aquela socióloga lembra que:

Pode-se distinguir o espaço econômico-social das atividades econômicas informais a partir de dois critérios distintos [...]. O primeiro desses critérios distingue o formal do informal a partir da respectiva lógica de funcionamento das atividades, isto é, se elas são atividades tipicamente capitalistas ou não, enquanto o segundo critério delimita essa diferença a partir da legalidade ou ilegalidade dessas atividades.

No entendimento dos adeptos desta primeira interpretação, que surgiu no início dos anos de 1970 a partir daquele estudo já mencionado sobre a estrutura produtiva e renda no Quênia, realizado por iniciativa da Organização Mundial do Trabalho - OIT no final dos anos 1960, a informalidade é conseqüência do excedente de mão de obra resultante do crescimento demográfico, sendo que na carência de mecanismos de proteção social e garantia de emprego a população excluída do mercado de trabalho teria se inserido no trabalho precário e informal como meio de sobrevivência. Nesta perspectiva a abordagem é investida tipicamente do valor lucro, onde a capacidade de determinar a lucratividade do sistema proporcionaria a criação de um contingente de trabalhadores subempregados ou na condição de "exercício industrial de reserva".

Para os adeptos do segundo entendimento, que teria nascido nos anos de 1970 a partir da realidade dos países capitalistas centrais, conforme lembra Druck (et.al. 2004), após a efervescência do Estado de bem estar, além do processo de reestruturação econômica com a liberação econômica, teria surgido às atividades não regulamentadas pelo Estado, conseqüentemente o aparecimento de formas de trabalho não tuteladas pela legislação e nem garantidas socialmente. Sobre essa perspectiva de abordagem a informalidade teria como critério de análise a questão da legalidade ou ilegalidade, em que a regulação pela via jurídica se insere como fator preponderante para entender o setor informal, o que teria influenciado o surgimento da precarização do setor produtivo como, por exemplo, a partir da economia subterrânea que inseriu atividades ocupacionais desprovidas de qualquer legalidade e de proteção dos direitos sociais, postos à margem das condições estruturais do capitalismo. 
Mesmo existindo diferentes modalidades de subordinação do trabalho informal ao capital, desde o simples preenchimento de um espaço no mercado de trabalho sem que haja qualquer relação de exploração ou extração de excedente, até formas mais diretas de subordinação onde estas relações existem (SOUZA, 1999, p. 136), desse modo,

\begin{abstract}
No primeiro caso, o núcleo capitalista da economia, nos seus movimentos de expansão e contratação, vai criando, destruindo e recriando espaços no mercado a serem preenchidos pela produção não tipicamente capitalista. No segundo caso, temos as formas de organização diretamente vinculadas por laços de subcontratação a uma empresa capitalista ou subordinação a um único capital onde se caracteriza a superexploração da mão de obra.
\end{abstract}

Há nesta modalidade econômica subterrânea uma subordinação deste espaço econômico ao capital, tornando o setor informal um elemento necessário no contexto produtivo capitalista, visto que a funcionalidade, por exemplo, do trabalho informal depende da dinâmica capitalista e se torna necessário ao sistema, "acerca da expansão e do modo como o trabalho informal está se relacionando com o capital, pode-se inferir que, caso essa tendência persista, a economia informal deixa de ser intersticial, como afirma a teoria da subordinação, para assumir a sua funcionalidade no sistema" (TAVARES, 2002, p. 52).

Neste sentido, o trabalho informal se adequou às necessidades do processo de acumulação de capital flexível, que tem sido a maneira de constituir as novas perspectivas e arranjos do setor produtivo no sistema produtivo capitalista. Para entender esse processo histórico de consecução do modelo flexível ${ }^{5}$ de acumulação que tem como uma de suas vertentes a questão da informalidade ressaltamos a configuração das relações de trabalho na industrialização. Ressaltando a questão do trabalho industrial, o fator que tem incrementado a desaceleração do emprego formal,

\footnotetext{
${ }^{5}$ Segundo Viana (2009, p.69-70) é necessário ressaltar uma critica a expressão "flexibilização", pois tal expressão pode significar desde a aptidão para fazer várias atividades até a submissão e docialidade. Neste caso, ao abordar as expressões "acumulação flexível", especialização flexível" e "aparato flexível" se percebe que a palavra é utilizada sobre diferentes perspectivas. Na verdade, o que se concebe com a flexibilização é a aptidão múltipla, ou seja, uma "inflexibilidade", pois os trabalhadores são submetidos ao objetivo de gerar o aumento da extração de mais valia relativa.
} 
industrial e qualificado é a intensificação do processo global de flexibilização ${ }^{6}$ das relações produtivas.

A expansão do trabalho informal acaba servindo como pressuposto da lógica capitalista de exploração a partir de índices mínimos de lucro aceitáveis pelos capitalistas. A mão de obra excedente desvinculada de qualquer proteção social tem de se submeter às formas de trabalho precário em conformidade com as condições de subempregos, marginalidade, precarização e dependência econômica ${ }^{7}$.

Nesse sentido, a questão das relações de trabalho na contemporaneidade perpassa as mudanças advindas com a globalização, sendo assim, a própria organização do trabalho nesta lógica acompanhou a estruturação produtiva do capitalismo, que insurgiu nas atividades industriais com o processo de acumulação flexível de capital ${ }^{8}$, garantindo com a industrialização e a mão-de-obra assalariada (além das formas precárias de empregabilidade ou subempregabilidade, além dos desempregados) um conjunto de trabalhadores presos a uma situação de alienação e com as condições de trabalho insalubres.

No entendimento de Castells (1999) a intensificação do modelo flexível acabou constituindo um novo modelo de sociedade dita "informacional" que se configurou numa relação societal dos processos de reestruturação produtiva empresarial a partir da organização da produção e do trabalho, cujo modelo produtivo baseia-se a partir de agora no toyotismo. Lembra também Alves (2009) que as formas de organização do trabalho e da produção neste contexto se caracterizam pela produção variada e bastante heterogênea, desenvolvida de forma horizontalizada, apoiando-se no princípio just in time, enquanto lógica de aproveitamento do tempo. Neste sentido, este modelo flexível de produção e controle do trabalho fez com que a produção estruturada a partir do processo produtivo flexível transforma-se o trabalhador num sujeito polivalente na operacionalização de diferentes tarefas e funções de forma a interligá-lo entre as atividades de concepção e execução.

\footnotetext{
${ }^{6}$ Esse processo de mudanças sinaliza aquilo que Harvey (1992) denominou de um novo modelo de acumulação, ou seja, a acumulação flexível de capital.

7 Para os economistas da Escola Neoclássica se acredita que a economia capitalista está voltada para concretização do pleno emprego, sendo que o contingente de trabalhadores empregados acaba dependendo dos níveis de salário e da fragilidade da força de trabalho. Neste caso, se compreende que a expansão do trabalho informal representa uma alternativa do trabalhador para se defrontar com um mercado de trabalho por vezes saturado ou com baixos salários (SOARES, 2008).

${ }^{8}$ Nesta fase, a acumulação flexível de capital se caracteriza pela "abertura comercial, pela liberação do mercado financeiro e pela flexibilização da legislação trabalhista, as políticas públicas adotadas sinalizam para atender os interesses dos capitalistas em detrimento dos trabalhadores" (SOARES, 2008, p. 144).
} 
Esta mudança trouxe consigo um novo paradigma comportamental na cultura da produção capitalista e na cultura operária, principalmente nas questões relacionadas ao trabalho, ao talento e ao consumo que foram se transformando a partir do aperfeiçoamento das tecnologias de comunicação e manufatura que se confrontam diretamente com as estruturas militares organizacionais dos moldes fordista e taylorista, quando o capitalismo aprendeu a cria mecanismos racionais de produção com a adoção de estruturas organizacionais que refletem a hierarquização de comando. Nesta conjuntura da cultura do novo capitalismo as corporações globais começam a rever processos e estruturas a uma velocidade alarmante, racionalizando o sistema produtivo e garantindo cada vez mais o lucro, graças à inserção de elementos como o talento necessário, a inovação tecnológica e o consumo (SANNETT, 2006).

A flexibilização tem incrementado novas formas de conceber a produção e o trabalho dentro deste contexto de mudanças dos processos e estruturas econômicas, no Brasil, por exemplo, em determinadas regiões do país, a questão da informalidade se intensifica com experiências do trabalho part-time, temporário, por tarefa, trabalho industrial domestico, que em tese seria trabalho formal, mas que incorpora elementos do setor formal e informal. Segundo Lima (2002), seria um retorno do ônus da reprodução da força de trabalho na própria família e o enfraquecimento da regulação do mercado de trabalho. Uma nova informalidade que incorpora trabalhadores antes inseridos no mercado formal e protegido.

Para o sistema capitalista ao operacionalizar suas estratégias produtivas em regiões ou nos países em desenvolvimento ${ }^{9}$ e nos países de economia estagnada, que possuem pouca ou nenhuma industrialização, se constata medidas mais severas de exploração da mão de obra, principalmente com aumento da jornada de trabalho tendo em vista combater a queda da taxa de lucros, logo a flexibilização se constitui como uma ferramenta econômica propicia a lógica do modelo globalização econômica, principalmente ao minimizar a proteção social jurídico-legal e deixar o espaço livre para a ação do capital.

\footnotetext{
${ }^{9}$ Alerta Viana (2009) que no Brasil a implantação do toyotismo ocorre de forma lenta e contraditória, tanto devido ao atraso tecnológico em relação aos países imperialistas quanto pela resistência patronal (com a utilização de tecnologia avançada que aumenta os custos de produção) quanto do operariado.
} 


\section{CONSIDERAÇÕES FINAIS}

A globalizada suscita um debate sobre a questão da produção da acumulação de riquezas a partir de uma nova divisão internacional do trabalho, principalmente numa perspectiva de exclusão social, visto que na conjuntura atual não vingou a assistência governamental de garantia dos direitos sociais, particularmente a garantia do trabalho, tendo em vista o fim do modelo Welfare State, significando uma ruptura com o modelo assistencial do pós-guerra, principalmente com a efervescência da dinâmica econômica neoliberal.

Nesse sentido, a globalização constituiu um modelo econômico capitalista industrial reforçado pelas desigualdades estruturais, tendo como elemento preponderante para este processo a flexibilização de aspectos como as relações de trabalho, gerenciamento dos espaços de deliberação política, da autonomia dos Estados Nacionais, do fortalecimento da economia e das estruturas sociais regionais e locais. A abertura do mercado imposta por esta conjuntura neoliberal, nascido a partir dos ditames do Consenso de Washington, trouxe consigo dificuldades nas indústrias nacionais, que não conseguem seguir a dinâmica produtiva, tecnológica e informacional das economias transnacionais.

O capitalismo global tornou os países desenvolvidos e subdesenvolvidos presos às exigências tecnológicas e de remoção das fronteiras territoriais, causando o enfraquecimento dos Estados Nacionais, entre outras razões pelos efeitos da globalização, que intensificam a pobreza, as deficiências regionais, além de favorecer um dos grandes "horrores econômicos" da contemporaneidade, que se revela na expansão do desemprego estrutural que intensifica os índices de vulnerabilidade da mão de obra precária, flexível e de insegurança político-jurídica. Aquele processo de acumulação flexível, dentro do processo econômico da globalização uma aptidão múltipla, para que os trabalhadores se submetessem as piores condições de emprego, subemprego e desemprego tendo em vista o incremento da mais valia relativa (VIANA, 2009).

Esse processo histórico de consecução do modelo flexível de acumulação que tem como uma de suas vertentes a questão da informalidade configurou medidas mais severas de exploração da mão de obra, principalmente com aumento da jornada de trabalho tendo em vista combater a queda da taxa de lucros, logo a flexibilização 
acaba sendo a saída para interferir nas legislações trabalhistas, procurando minimizar a proteção social jurídico-legais e deixar o espaço livre para a ação do capital.

\section{REFERÊNCIAS}

BAUMAN, Zygmunt. Globalização: as conseqüências humanas. Rio de Janeiro: Jorge Zahar, 1999.

. Em busca da política.Rio de Janeiro: Ed. Zahar, 2000.

. Modernidad liquida. Buenos Aires. Fondo de Cultura Econômica, 2006.

BECK, Ulrich. O que é globalização? equívocos do globalismo: respostas à globalização. São Paulo: Paz e Terra, 1999.

BOLTANSKI, Luc; CHIAPELLO, Éve. O novo espírito do capitalismo. São Paulo. Martins fontes, 1999.

CASTELLS, Manuel. A empresa em rede: a cultura, as instituições e as organizações da economia informacional. In. . A Sociedade em Rede. 4. ed. São Paulo: Paz e Terra, 2000. Vol. 1.

CASTEL, Robert. As metamorfoses da questão social: uma crônica do salário. Tradução Iraci D. Poleti. Petrópolis, RJ: Vozes, 1998.

DUCK, Graça et. al. O conceito de informalidade: um exercício de aplicação empírica. Caderno CRH. Salvador, v. 17, n. 41. Mai. Ago. 2004. 
GIDDENS, Anthony. As conseqüências da modernidade. São Paulo: Editora Unesp, 1991.

HABERMAS, Jürgen. Mudança estrutural da Esfera Pública: investigações quanto a uma categoria da sociedade burguesa. Rio de Janeiro: Tempo Brasileiro, 2002.

HALL, Stuart. A Identidade Cultural na Pós-Modernidade. Rio de Janeiro: DP\&A, 1990.

HARVEY, David. Fordismo à Acumulação Flexível. In. Condição PósModerna. São Paulo, Edições Loyola, 1992. Do

IANNI, Octávio. A sociedade global. 6 ed. Rio de Janeiro: Civilização Brasileira, 1998.

MARX, Karl. O Capital. Livro I. São Paulo: Nova Cultural, 1996. (Coleção os pensadores).

MENDES, José M. Amado. A História como Ciência: fontes, metodologia e teorização. Lisboa: ed. Coimbra, 1993.

OLIVEIRA, Roberto Véras de. Para discutir os termos da nova informalidade: a questão da informalidade enquanto uma categoria de análise válida para a apreensão da realidade atual das relações de trabalho. Campina Grande: UFCG, 2009.

OLIVEIRA, Roberto Véras de; MOREIRA, Eliana Monteiro. Introdução: Sentidos da globalização, um desafio ao pensamento sociológico. João Pessoa: UFPB, 2010. . 
SANTOS, Boaventura Sousa. Os processos da globalização. In. SANTOS, Boaventura Sousa (org.). A globalização e as ciências sociais. São Paulo: Cortez, 2005.

SENNETT, Richard. A cultura do novo capitalismo. Rio de Janeiro: Record, 2006.

SOARES, Marcos Antonio Tavares. Trabalho Informal: da funcionalidade à subsunção ao capital. Vitória da Conquista: Edições UEBS, 2008.

THERBORN, Göran. A crise do capitalismo. In. SADER, Emir; GENTILI, Pablo (Orgs.). Pós-neoliberalismo: as políticas sociais e o Estado democrático. 6.ed. São Paulo: Paz e Terra, 2003. p. 39-50.

\footnotetext{
${ }^{1}$ Licenciado em História e Bacharel em Direito (UEPB), pós-graduado em História da Filosofia (UFPB), mestre e doutorando em Ciências Sociais (PPGCS - UFCG). Pesquisador cadastrado no CNPq e membro do Grupo de Pesquisa "Trabalho, Desenvolvimento e Políticas Públicas" da Universidade Federal de Campina Grande UFCG. Professor dos Cursos de Direito das FIP e da FACISA. E-mail: marcelo.eufrasio@ gmail.com
}

RECEBIDO EM 02.06.2011

APROVADO EM: 18.06.2011 